\title{
Pharmacokinetics of morphine after intramuscular injection in common goldfish Carassius auratus and Atlantic salmon Salmo salar
}

\author{
Janicke Nordgreen $^{1, *}$, Hanne Hustoft Kolsrud ${ }^{2}$, Birgit Ranheim $^{1}$, \\ Tor Einar Horsberg ${ }^{1}$
}

${ }^{1}$ Department of Pharmacology and Toxicology, The Norwegian School of Veterinary Science, 0033 Oslo, Norway

${ }^{2}$ Department of Chemistry, The University of Oslo, 0316 Oslo, Norway

\begin{abstract}
Teleost fish have a nociceptive system and likely perceive pain. This warrants the development of analgesic protocols both for experimental surgery and for various husbandry procedures. Morphine is the standard analgesic against which the efficacy of other analgesics is assessed, and is the analgesic that has been most used in fish. The aims of this study were to describe the pharmacokinetics of morphine after an intramuscular (i.m.) injection in common goldfish and Atlantic salmon, and to illustrate the whole-body distribution of morphine in salmon following i.m. injection of tritiated morphine. In the kinetic experiment, goldfish and salmon were respectively i.m. injected with 40 and $100 \mathrm{mg}$ morphine $\mathrm{kg}^{-1}$ in the right dorsal epaxial musculature. Blood was drawn at predetermined time points. Plasma was analysed for morphine and metabolites using liquid chromatography-mass spectrometry (LC-MS/MS). Morphine had a $T_{\max }$ (time at which the maximum plasma concentration was measured) of $0.5 \mathrm{~h}$ in both species. The $C_{\max }$ (maximum plasma concentration) showed substantial inter-individual variation, with a mean (90\% CI) of 187 (167 to 199) $\mathrm{mg} \mathrm{l}^{-1}$ in salmon and 37 (29 to 43) $\mathrm{mg} \mathrm{l}^{-1}$ in goldfish, as determined by bootstrap analysis. The mean elimination half-lives were 12.5 and $13.5 \mathrm{~h}$ in goldfish and in salmon, respectively. The degree of metabolism to morphine-3-glucuronide (M3G) and morphine-6-glucuronide (M6G) was low, with levels of M3G exceeding those of M6G. The distribution study demonstrated that the levels of tritiated morphine in the anterior kidney surpassed those in the other organs. A substantial amount seemed to be excreted through the gastrointestinal tract, while little tritium activity could be detected in the central nervous system.
\end{abstract}

KEY WORDS: Morphine $\cdot$ Teleost $\cdot$ Goldfish $\cdot$ Salmon $\cdot$ Distribution $\cdot$ Autoradiography

\section{INTRODUCTION}

There is now growing evidence that the nervous system of teleosts can detect noxious stimuli (Ashley et al. 2007), and that fish may perceive pain (Braithwaite \& Boulcott 2007). Although the debate over this question is still strong (Rose 2007), this warrants the development of analgesic protocols both for experimental surgery and for different husbandry procedures. This is reflected in e.g. the recommendations of the Canadian Council of Animal Care (www.ccac.ca/en/CCAC_ Programs/Guidelines_Policies/GDLINES/Guidelis.htm).
The use of anaesthetics such as MS-222 and benzocaine in fish is relatively widespread. However, their analgesic effect is not properly documented. These agents are administered through the water, are rapidly absorbed over the gills, but are also rapidly excreted when the fish are removed from the anaesthetic bath. Thus, they are not good candidates for the treatment of long-lasting or severe pain.

Morphine is the standard opioid analgesic against which the efficacy of new opioid analgesics is assessed (Rang et al. 1999), and most experiments on the pharmacokinetics and pharmacodynamics of analgesics in 
fish have focused on morphine. In rainbow trout, goldfish and winter flounder, morphine has shown antinociceptive effects (Ehrensing et al. 1982, Sneddon 2003, Newby et al. 2007, Newby et al. 2009). However, the doses used have been high compared to those needed to obtain effects in mammals, with 40 to $3000 \mathrm{mg}$ morphine $\mathrm{kg}^{-1}$ being injected intraperitoneally or intramuscularly in fish, compared to $1 \mathrm{mg}$ $\mathrm{kg}^{-1}$ for rats (King et al. 2007). The few existing studies on the pharmacokinetics of opioids in fish have revealed interspecific differences in the disposition of morphine (Newby et al. 2006, Newby et al. 2008, Newby et al. 2009). Therefore, more research is needed on the pharmacokinetics of morphine and its metabolites in different fish species before analgesic protocols can be suggested and validated.

In humans, morphine is metabolized in several ways, the most important of which being its conjugation with glucuronic acid in the liver (Andersen et al. 2003). In humans, 44 to $55 \%$ of morphine is metabolised to morphine-3-glucuronide (M3G), 8 to $10 \%$ is metabolised to morphine-6-glucuronide (M6G), whereas $10 \%$ is excreted unchanged in the urine along with most of the conjugated morphine (Hasselström \& Säwe 1993, Andersen et al. 2003). M3G is essentially inactive, or may even antagonise the antinociceptive effects of morphine (Smith et al. 1990, Hewett et al. 1993, Andersen et al. 2003), whereas M6G has analgesic effects in mammals (reviewed by Dahan et al. 2008). In the only study of its kind, M3G, but not M6G was detected in the plasma of rainbow trout (Newby et al. 2008).

To the authors' knowledge, the pharmacokinetics of morphine has not been previously studied in Atlantic salmon, and the distribution of morphine in different tissues has not been described in any teleost species.

The aims of this study were to (1) describe the pharmacokinetics of morphine and the metabolites M3G and M6G, after intramuscular (i.m.) injection in common goldfish Carassius auratus and in the Atlantic salmon Salmo salar, and (2) illustrate the whole-body distribution of morphine following i.m. injection of tritiated morphine in salmon. Goldfish and salmon were chosen based on their importance in research and aquaculture, respectively.

\section{MATERIALS AND METHODS}

Pharmacokinetics. Thirty common goldfish (mean weight: $29.2 \mathrm{~g}$, range: 22.0 to $44.0 \mathrm{~g}$ ) were purchased from a local breeder. The fish were fed with commercial goldfish feed once a day both before and during the experiment, but were fasted on the day of injection. Three days before injection, they were moved into the experimental tanks (80 l) in pairs. The tanks were run on a recirculation system (renewal rate: $20 \% \mathrm{~d}^{-1}$ ) and air was supplied by air pumps. The temperature in the tanks was $16 \pm 0.5^{\circ} \mathrm{C}$, reflecting the temperature in the room. On the injection day, fish were transferred to a bath with 150 mg metacaine $\mathrm{l}^{-1}$ (Finquel, Argent Laboratories) until they did not respond to light pinching of the tail ( $7 \mathrm{~min})$, weighed and i.m. injected with $40 \mathrm{mg}$ morphine $\mathrm{kg}^{-1}$ (morphine hydrochloride, $20 \mathrm{mg} \mathrm{ml}^{-1}$; Nycomed Pharma). The injection was given in the right dorsal epaxial musculature. At each of 5 time points $(0.5,1,1.5,4$ and $24 \mathrm{~h})$ after injection, 6 goldfish were anaesthetised (metacaine, $400 \mathrm{mg} \mathrm{l}^{-1}$ for $\sim 5 \mathrm{~min}$ ), subjected to blood sampling with a 26 gauge needle and subsequently sacrificed by spinal severance. Blood was sampled from the caudal vein using heparincoated syringes, and transferred to blood-collection tubes with lithium heparin (Terumo). After centrifugation, the plasma was kept at $-80^{\circ} \mathrm{C}$ until analysis for morphine and metabolites by liquid chromatographymass spectrometry (LC-MS/MS).

Fifty-four Atlantic salmon in the parr-stage (Aquagen stock; mean weight: $66 \mathrm{~g}$, range: 39 to $94 \mathrm{~g}$ ) were transferred to $70 \mathrm{l}$ experimental tanks $2 \mathrm{wk}$ prior to the start of the experiment. The fish were kept in groups of 6 . The tanks were on a flow-through fresh water system, with air being supplied by air pumps. The temperature was $8.7 \pm 0.2^{\circ} \mathrm{C}$, reflecting the temperature of the inlet water.

On the day of injection, the fish were anaesthetised in a metacaine bath (100 $\mathrm{mg} \mathrm{l}^{-1}$ for 0.5 to $1 \mathrm{~min}$ ), weighed and i.m. injected with $100 \mathrm{mg}$ morphine $\mathrm{kg}^{-1}$. The injection was given in the right dorsal epaxial musculature. At each of 9 time points $(0.5,1,1.5,4,8$, $16,24,72$ and $96 \mathrm{~h}$ ) after injection, 6 fish were anaesthetised in metacaine (100 $\mathrm{mg} \mathrm{l}^{-1}$ for 2 to $3 \mathrm{~min}$ ) and blood was sampled prior to sacrificing the fish by spinal severance. The blood sample was drawn from the caudal vein, treated and stored as the goldfish samples.

LC-MS/MS analysis. The LC-MS/MS method used was based on Newby et al. (2008) with some modifications. Standard curves for morphine were prepared by adding morphine (morphine hydrochloride, $20 \mathrm{mg}$ $\mathrm{ml}^{-1}$; Nycomed Pharma) to drug-free trout plasma to concentrations of $0.25,0.50,1.0,2.5,5.0,10,25,50,75$ and $100 \mathrm{mg} \mathrm{l}^{-1}$. Standard curves for the M3G and M6G metabolites (Sigma-Aldrich) were prepared by adding the respective metabolite to drug-free trout plasma to concentrations of $0.05,0.10,0.20,0.50$ and $1.0 \mathrm{mg} \mathrm{l}^{-1}$. Standard curves were run for each series of samples. Naloxone (Sigma-Aldrich) served as the internal standard, and was added to a concentration of $1.6 \mathrm{mg} \mathrm{l}^{-1}$ to the experimental plasma samples and the spiked drugfree trout plasma, before protein precipitation was carried out in the following way: 2 aliquots of $70 \mu \mathrm{l}$ of ice- 
cold acetonitrile with $0.1 \%$ acetic acid were added to $100 \mu \mathrm{l}$ of plasma/spiked plasma standards and vortexed. The samples were allowed to rest on ice for $15 \mathrm{~min}$ before being centrifuged at $14000 \times g$ for $10 \mathrm{~min}$. The supernatant was collected and centrifuged through a $0.22 \mu \mathrm{m}$ nylon filter (Spin-X, Costar) at $14000 \times g$ for $2 \mathrm{~min}$. The filtrate was evaporated using $\mathrm{N}_{2}$ (45 min), and the samples were then reconstituted in $100 \mu \mathrm{l}$ of purified water before they were transferred to HPLC vials. The separations were carried out on an HPLC System (HP 1100 Series, Agilent) with a Hypersil GOLD column $(100 \times 2.1 \mathrm{~mm}, 3 \mu \mathrm{m}$; Thermo Scientific) that was equipped with a pre-column and an inline filter. The injection volume was $5 \mu \mathrm{l}$. The mobile phase consisted of methanol, water and $10 \mathrm{mM}$ of ammonium acetate. It was run in gradient mode with $10 \%$ methanol in water from 0 to $3 \mathrm{~min}$, thereafter increasing linearly to $55 \%$ methanol at 5 min before decreasing linearly to $10 \%$ methanol at $8 \mathrm{~min}$ after injection of the sample. The total runtime was $18 \mathrm{~min}$. At a flow rate of $0.3 \mathrm{ml} \mathrm{min} \mathrm{m}^{-1}, \mathrm{M} 3 \mathrm{G}, \mathrm{M} 6 \mathrm{G}$, morphine and naloxone eluted at $\sim 1.9,3.6,7.7$ and 9.9 min after injection, respectively. The mass spectrometric analyses were done on a tandem mass spectrometer (Sciex API-3000, Applied Biosystems/MDS Sciex) using electrospray ionization (ESI) selective ion recording in positive-ion mode. The instrument was tuned for each individual component, and optimal parameters for capillary temperatures, voltages, collision energies and sheath gas volumes were used. The sensitivity of the method was increased by operating the instrument in selective ion monitoring (SIM) mode. The ions chosen were the daughter ions giving the best signal in a full scan MS/MS mode. The ion mass transitions monitored were $286.2 \rightarrow 165.0$ (morphine), $462.2 \rightarrow 286.0$ (M3G and M6G) and 328.2 $\rightarrow 310.1$ (naloxone). The chromatograms were integrated using Analyst Software 1.4.2 (Applied Biosystems). The concentrations were calculated by comparing the peak areas in the samples with the appropriate standard curves generated from the spiked samples.

The limit of detection for morphine, M3G and M6G was $0.001 \mathrm{mg} \mathrm{l}^{-1}$, which was determined as a peak giving a signal of $3 \times$ the baseline noise at the respective retention time in drug-free plasma samples. The method was validated for morphine in 2 concentration ranges: 0.25 to 5 and 5 to $120 \mathrm{mg} \mathrm{l}^{-1}$. The linearity was good in both ranges $\left(\mathrm{R}^{2}>0.994\right)$. The repeatability for morphine $(\mathrm{N}=6)$ at $1 \mathrm{mg} \mathrm{l}^{-1}$ had a coefficient of variation $(\mathrm{CV})$ of $5.7 \%$, while that at $15 \mathrm{mg} \mathrm{l}^{-1}(\mathrm{~N}=6)$ had a CV of $12.5 \%$. Recovery (determined by comparing signals at a spiking concentration of $2.5 \mathrm{mg} \mathrm{l}^{-1}$ (morphine) or $0.05 \mathrm{mg} \mathrm{l}^{-1}$ (metabolites) with a standard of the same concentration) was 92,83 and $81 \%$ for morphine, M3G and M6G, respectively. The linearity for the metabo- lites in the concentration range 0.05 to $1.0 \mathrm{mg} \mathrm{l}^{-1}$ was good $\left(R^{2}>0.993\right)$. Repeatability was not determined for the metabolites. The internal standard (naloxone) was used for quality control of each individual sample. It was not used for quantification.

Scintillation counting and autoradiography. Twelve salmon (mean weight: $55 \mathrm{~g}$, range: 29 to $66 \mathrm{~g}$ ) were kept in pairs in the same tanks as described for goldfish in $\operatorname{Exp} 1$. The fish were injected with $29 \pm 1 \mathrm{mg}$ tritiated morphine $\mathrm{kg}^{-1}\left(460 \pm 20 \mu \mathrm{Ci} \mathrm{kg}{ }^{-1}\right)$ in the dorsal epaxial musculature on the right side, and $44 \pm 2 \mathrm{mg}$ unlabelled morphine $\mathrm{kg}^{-1}$ on the left side. At each of 6 time points $(0.5,1,4,8,16$ and $24 \mathrm{~h})$ after injection, 2 fish were sacrificed by an overdose of benzocaine (400 $\left.\mathrm{mg} \mathrm{l}^{-1} ; 15 \mathrm{~min}\right)$. They were kept frozen at $-80^{\circ} \mathrm{C}$ until sectioning for autoradiography and sampling for the scintillation count.

Six of the 12 salmon were frozen whole in chilled carboxymethylcellulose in water for whole-body autoradiography (WBA). From the remaining 6 salmon, only the head was prepared for transverse section autoradiography. The blocks were immediately frozen on dry ice and kept at $-20^{\circ} \mathrm{C}$ until sectioning. Sagittal sections for WBA and transverse sections of the head (all $20 \mu \mathrm{m}$ thick) were cut at different levels on a cryomicrotome (PMV), and collected on tape no. 821 (3M). The sections were freeze dried overnight before application on an Amersham Hyperfilm MP (Amersham/GE Healthcare) at $-80^{\circ} \mathrm{C}$ for 6 mo.

From the remaining material, samples of 1 to $78 \mathrm{mg}$ were taken from the skin, blood, muscle (white and red), liver, kidney (anterior and posterior) and the spinal cord. Brain tissue from fish subjected to transverse sectioning of the head was not available for scintillation counting. For sagittally sectioned fish, brain samples were not consistently available from all areas, as some fish were sectioned past their mid line. Thus, only a few samples from the brain were analysed. Each sample was digested overnight with $1 \mathrm{ml}$ Soluene (Packard) at $37^{\circ} \mathrm{C}$, before addition of $10 \mathrm{ml}$ liquid scintillation cocktail (Hionic Fluor, Packard). Radioactivity in the sample was counted in a liquid scintillation analyser (Packard Tri-Carb 1900CA). Counting efficiency was controlled by counting samples from untreated salmon before and after spiking with a standardised tritiated reagent containing 1000 dpm (disintegrations per minute).

Results from the scintillation count are presented as concentrations of morphine in different organs relative to that in blood. Results from autoradiography are described qualitatively.

Data analysis and calculation of pharmacokinetic parameters. Concentration versus time data for the plasma morphine concentrations were subjected to noncompartmental modelling using 2 different meth- 
ods: the pooled sample approach and bootstrapping. The formulas for calculating the pharmacokinetic parameters were the same in both methods.

The pooled sample approach is normally used to model data from studies using the current experimental protocol. The mean concentration is calculated for each sampling time, and these mean values are used to model the results. The pharmacokinetic parameters are estimated by calculating the terminal slope and the area under the concentration versus time curve (AUC), using the linear or linear/log trapezoidal rule, extrapolated to infinity. This was done using the pharmacokinetic software WinNonlin ver. 4.2 (Statistical Consultants). However, as the values at each time point were obtained from different individuals, the standard error of the mean that is calculated by this method does not give an accurate estimate of the uncertainty of the pharmacokinetic parameters calculated. To be able to calculate CIs for the pharmacokinetic parameters, we therefore reanalysed the pharmacokinetic data using bootstrapping (Davison \& Hinkley 1997, Carpenter \& Bithell 2000, Urien et al. 2005). The idea of bootstrapping in pharmacokinetic studies is to resample from the original data to construct many new hypothetical concentration versus time curves. This was done in the following way: 6 random concentration values were sampled with replacement from the first sampling time, and their mean calculated. This was combined with a value from the second sampling time obtained in the same way. These 2 were combined with a corresponding value from the third sampling time. The dataset obtained in the end can be thought of as belonging to 1 'virtual fish'. This hypothetical concentration versus time curve was then subjected to pharmacokinetic modelling (as in the pooled data approach). This procedure was repeated 2500x. CIs $(90 \%)$ were then constructed from these 2500 pharmacokinetic parameter estimates (bootstrap replicates) by using the bias-corrected and accelerated (BCa) method (Efron 1987, Efron \& Tibshirani 1993, Carpenter \& Bithell 2000). The procedure was carried out using the statistical software SAS ver. 6.12 (SAS Institute).

In the calculation of the negative exponential coefficient for the terminal part of the concentration versus time curve $\left(\lambda_{z}\right)$, linear regression of the logarithmically transformed values of the last 4 sampling time points was used. The half-life for elimination $\left(t_{1 / 2} \lambda_{z}\right)$ was calculated as $\ln (2) / \lambda_{z}$. The bioavailability, $F$, was not known, but is normally close to $100 \%$ after an i.m. injection of an aqueous, non-irritating solution (Baggot 2001). Values for the volume of distribution $\left(V_{z}\right)$ and clearance $\left(C l_{\mathrm{T}}\right)$ are expressed relative to the unknown $F\left(V_{z} F^{-1}=\right.$ the volume of distribution relative to bioavailability; $\mathrm{Cl}_{\mathrm{T}} \mathrm{F}^{-1}=$ the total body clearance rela- tive to bioavailability); however, because of the high bioavailability following i.m. injection, the absolute values are most likely not very different from the relative values given. $\mathrm{Cl}_{\mathrm{T}}$ was calculated as dose/AUC $\infty$ where $\mathrm{AUC} \infty$ is the area under the curve that was extrapolated to infinity. $V_{\mathrm{z}}$ was calculated as dose/ $\left(\mathrm{AUC} \infty \lambda_{z}\right)$.

\section{RESULTS}

\section{Pharmacokinetics}

The pharmacokinetic parameters determined using both the pooled sample and the bootstrap approach with $90 \%$ CIs are presented in Tables 1 \& 2 . All parameters obtained with the pooled data approach were within the $90 \%$ CI calculated by bootstrap analysis. Morphine increased rapidly in plasma after the i.m. injection, with a $T_{\max }$ (the time at which the maximum plasma concentration of morphine was measured) of $0.5 \mathrm{~h}$ in both species. The maximum plasma concentration of morphine $\left(C_{\max }\right)$ showed substantial inter-individual variation, with a mean $(90 \% \mathrm{CI})$ of 187 (167 to 199) $\mathrm{mg} \mathrm{l}^{-1}$ for salmon and 37 (29 to 43 ) $\mathrm{mg} \mathrm{l}^{-1}$ for goldfish, as determined using the bootstrap approach.

In goldfish, the mean elimination half-life for morphine was $12.5 \mathrm{~h}$. The disposition curves for plasma morphine, M3G and M6G in goldfish are shown in

Table 1. Carassius auratus. Pharmacokinetic parameters for morphine in individuals with an average weight of $29.2 \mathrm{~g}$ and kept at $16^{\circ} \mathrm{C}$ in semistatic fresh water. $\mathrm{R}^{2}$ : goodness of fit statistic for the terminal elimination phase; $T_{\max }$ : the time at which the maximum plasma concentration of morphine was measured; $C_{\max }$ : the maximum plasma concentration of morphine; AUC $\infty$ : the area under the concentration versus time curve extrapolated to infinity; AUC ex.: the percentage of AUC $\infty$ that is constituted by the extrapolated area; $\lambda_{z}$ : the negative exponential coefficient for the terminal part of the concentration versus time curve; $t_{1} / 2 \lambda_{z}$ : the elimination halflife; $V_{z} F^{-1}$ : the volume of distribution relative to bioavailability; $\mathrm{Cl}_{\mathrm{T}} \mathrm{F}^{-1}$ : the total body clearance relative to bioavailability. Bootstrapping results are given as means (90\% CI)

\begin{tabular}{|lccc|}
\hline Parameters & Units & $\begin{array}{c}\text { Pooled data } \\
\text { approach }\end{array}$ & $\begin{array}{c}\text { Bootstrap approach } \\
(90 \% \mathrm{CI})\end{array}$ \\
\hline Dose & $\mathrm{mg} \mathrm{kg}^{-1}$ & 40 & \\
$\mathrm{R}^{2}$ & & 0.978 & 0.5 \\
$T_{\max }$ & $\mathrm{h}$ & 0.5 & $37(29-43)$ \\
$C_{\max }$ & $\mathrm{mg} \mathrm{l}^{-1}$ & 37 & $590(441-848)$ \\
$\mathrm{AUC} \infty$ & $\mathrm{mg} \mathrm{h}^{-1}$ & 612 & \\
$\mathrm{AUC}$ ex. & $\%$ & 32 & $0.055(0.033-0.083)$ \\
$\lambda_{z}$ & $\mathrm{~h}^{-1}$ & 0.049 & $12.5(8.4-20.8)$ \\
$t_{1} \lambda_{z}$ & $\mathrm{~h}$ & 14.3 & $1.23(0.96-1.52)$ \\
$V_{\mathrm{z}} F^{-1}$ & $1 \mathrm{~kg}^{-1}$ & 1.35 & \\
$\mathrm{Cl}_{\mathrm{T}} F^{-1}$ & $1 \mathrm{~h}^{-1} \mathrm{~kg}^{-1}$ & 0.065 & $0.068(0.048-0.091)$ \\
& & & \\
\hline
\end{tabular}


Table 2. Salmo salar. Pharmacokinetic parameters for morphine in individuals with an average weight of $66 \mathrm{~g}$ and kept at $8^{\circ} \mathrm{C}$ in running fresh water. Abbreviations are as in Table 1

\begin{tabular}{|lccc|}
\hline Parameters & Units & $\begin{array}{c}\text { Pooled data } \\
\text { approach }\end{array}$ & $\begin{array}{c}\text { Bootstrap approach } \\
(90 \% \mathrm{CI})\end{array}$ \\
\hline Dose & $\mathrm{mg} \mathrm{kg}^{-1}$ & 100 & \\
$\mathrm{R}^{2}$ & & 0.996 & 0.5 \\
$T_{\max }$ & $\mathrm{h}$ & 0.5 & $187(167-199)$ \\
$C_{\max }$ & $\mathrm{mg} \mathrm{l}^{-1}$ & 187 & $1353(1222-1463)$ \\
$\mathrm{AUC} \infty$ & $\mathrm{mg} \mathrm{h}^{-1}$ & 1354 & \\
$\mathrm{AUC}$ ex. & $\%$ & 0.6 & $0.051(0.045-0.056)$ \\
$\lambda_{z}$ & $\mathrm{~h}^{-1}$ & 0.047 & $13.5(12.3-15.4)$ \\
$t_{1} / 2$ & $\mathrm{~h}$ & 14.8 & $1.45(1.28-1.67)$ \\
$V_{z} F^{-1}$ & $1 \mathrm{~kg}^{-1}$ & 1.58 & $0.074(0.068-0.082)$ \\
$C l_{\mathrm{T}} F^{-1}$ & $\mathrm{l} \mathrm{h}^{-1} \mathrm{~kg}^{-1}$ & 0.074 & \\
& & & \\
\hline
\end{tabular}

Fig. 1. The concentration of M3G increased starting at 0.5 to $24 \mathrm{~h}$ post-injection. M6G was detected in only 3 of the $64 \mathrm{~h}$ samples and in all $24 \mathrm{~h}$ samples.

In salmon, the mean elimination half-life for morphine was $13.5 \mathrm{~h}$. The disposition curves for plasma morphine and the metabolites M3G and M6G are shown in Fig. 2. The plasma concentration of M3G increased starting at 0.5 to $12 \mathrm{~h}$ before it started to decrease. M6G was detected in all samples at all time points.

The concentrations of M6G were close to the limit of detection in all samples from both species, and were below the lowest concentration used in the standard curve. Thus, exact values cannot be reported, although an estimation of concentrations was made by extrapo-

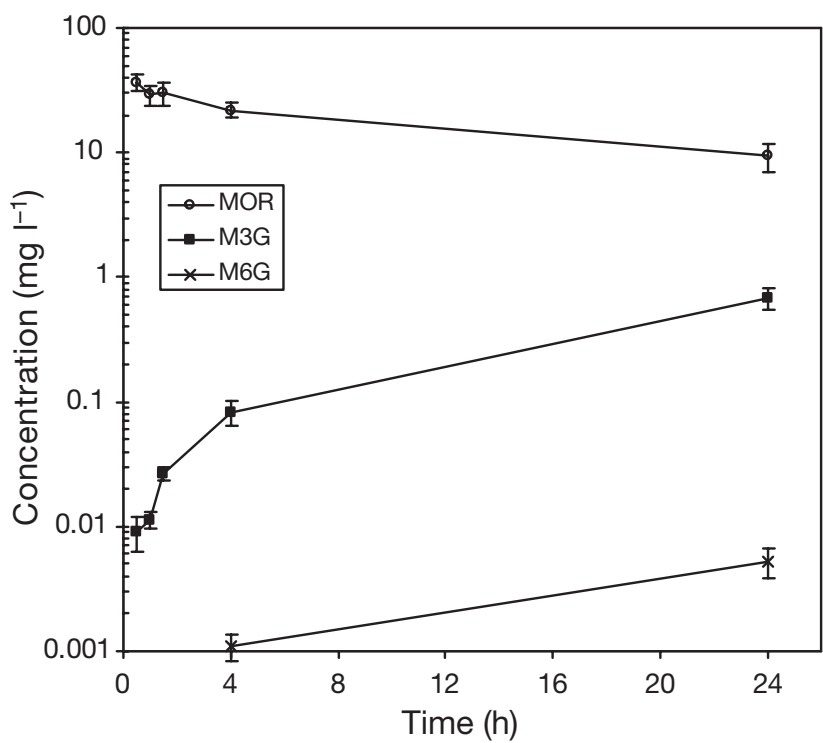

Fig. 1. Carassius auratus. Plasma concentrations $( \pm$ SEM) of morphine (MOR) and the metabolites M3G and M6G after a single intramuscular injection of $40 \mathrm{mg} \mathrm{kg}^{-1}$ at time 0 , on a semilogaritmic scale

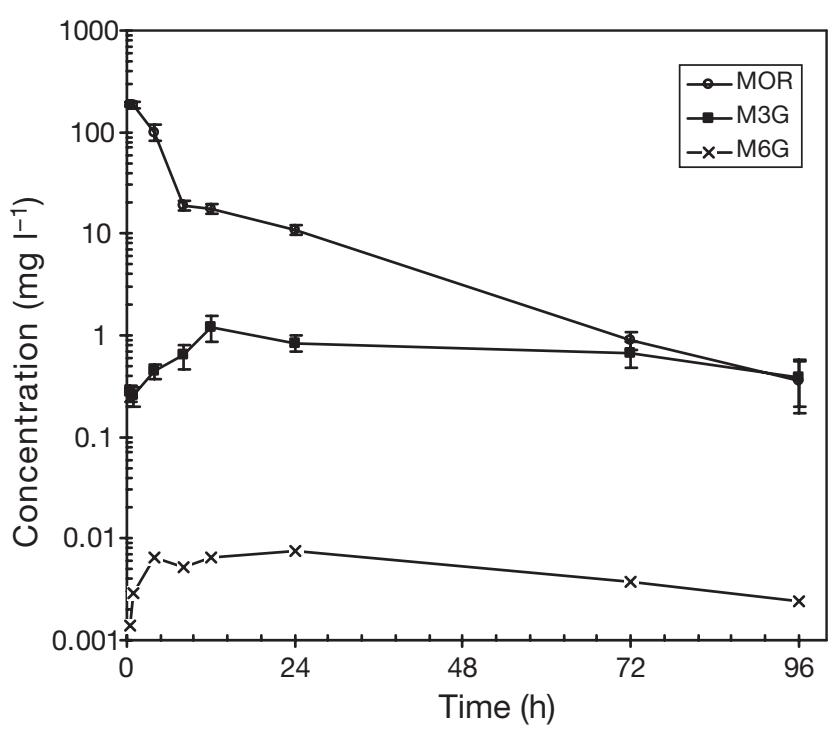

Fig. 2. Salmo salar. Plasma concentrations $( \pm$ SEM $)$ of morphine (MOR) and the metabolites M3G and M6G after a single intramuscular injection of $100 \mathrm{mg} \mathrm{kg}^{-1}$ at time 0 , on a semilogaritmic scale

lating the standard curves. This extrapolation indicated that the plasma profiles of M6G were similar to those of M3G, but that the concentration was approximately one magnitude lower (Figs. 1 \& 2). However, the curve for M6G must be interpreted with caution.

\section{Scintillation count and autoradiography}

The levels of morphine in the tissues sampled relative to the level in blood are shown in Fig. 3. The levels were highest in the anterior kidney, posterior kidney and liver. In red muscle, white muscle and skin, the levels fell below the levels in blood at some time points, while the levels in the spinal cord were lower than or approximately similar to the blood levels of tritiated morphine (results shown for skin and spinal cord). The few samples of different brain areas available indicated similar or lower levels than in the spinal cord (data not shown).

Results from the whole-body autoradiography supported those of the scintillation counts. However, the sensitivity of the autoradiographic method was lower than that of the scintillation method. Very little radioactivity was observed at $0.5 \mathrm{~h}$, but activity was seen in the posterior and anterior kidney at $1 \mathrm{~h}$, with most activity being seen in the anterior kidney (Fig. 4). At this time point, activity was also detected in the liver and in the walls of the gastrointestinal tract. At $4 \mathrm{~h}$, activity in the posterior intestine dominated, and radioactivity was also detected in the urinary bladder and kidney. Activity in the liver was low at this time 


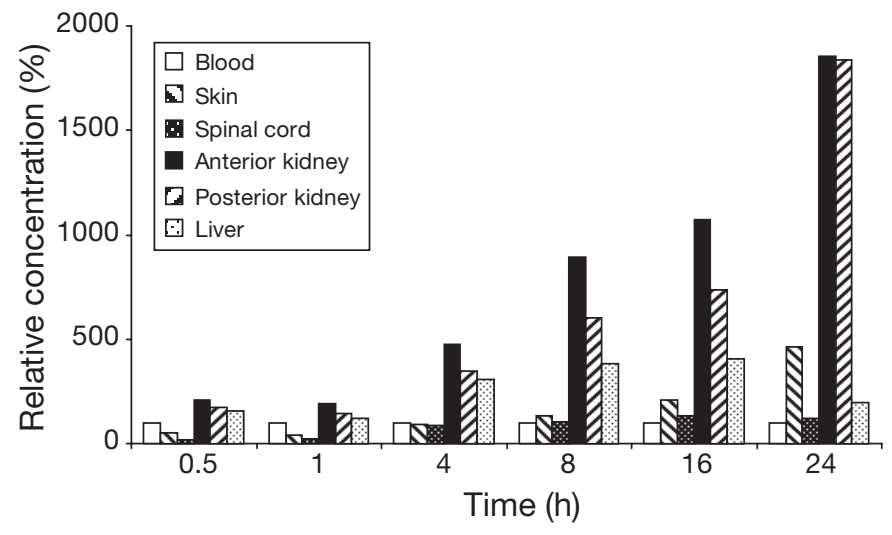

Fig. 3. Salmo salar. Concentration of tritiated morphine in different tissues relative to blood at 6 different time points after injection. For all columns except blood at $1 \mathrm{~h}$, spinal cord at $4 \mathrm{~h}$ and liver at $24 \mathrm{~h}, \mathrm{n}=2$

point, but appeared higher after $8 \mathrm{~h}$ together with clearly visible caudal gastrointestinal tract activity, and weaker urinary bladder activity. At 16 and $24 \mathrm{~h}$, no radioactivity could be detected in the liver. The $24 \mathrm{~h}$ finding fits with the declining curve for levels in liver relative to that in blood (Fig. 3). Unfortunately, the $24 \mathrm{~h}$ section did not include kidney tissue. No activity was observed in the spinal cord or in the transverse brain sections.

\section{DISCUSSION}

\section{Pharmacokinetics}

In the pharmacokinetic experiment, we chose the respective doses of 40 and $100 \mathrm{mg} \mathrm{kg}^{-1}$ in goldfish and salmon based on work published by other laboratories and experiments carried out by our group: the pharmacokinetics and dynamics of morphine in winter flounder following an injection of $40 \mathrm{mg} \mathrm{kg}^{-1}$ have been described (Newby et al. 2006, 2007), and this prompted studies using the same dose in goldfish (Nordgreen et al. 2009). However, the results from our pharmacodynamic experiment did not yield unequivocal results, and based on experiments on amphibians (Pezalla 1983), we therefore increased the dose for the pharmacokinetic experiments in salmon to $100 \mathrm{mg} \mathrm{kg}^{-1}$.

In this experiment, blood samples were only drawn once from each fish due to their small size and correspondingly small blood volume. This single individual-single sample design limits handling stress for each fish, but has its drawback when the results are modelled (Horsberg 1994). The alternative approach, i.e. serial samples from the same individual and calculation of individual pharmacokinetic parameters, has other drawbacks. Each fish must be considerably larger than the fish used in the present study to allow multiple samples to be drawn from the same individual, and the stress of the repeated sampling procedures may jeopardize the results. The sampling stress may be overcome by implanting a permanent cannula in the dorsal aorta of the fish (Soivio et al. 1975), provided it is $>500 \mathrm{~g}$. However, cannulation itself may affect pharmacokinetic parameters due to decreased activity, diminished food intake and blood loss (Martinsen et al. 1993, Sohlberg et al. 1994, 1996).

Because of the aforementioned flaws in the single individual-single sample design, we also analysed the data by bootstrapping to allow calculation of CIs for the pharmacokinetic parameters. This enabled us to compare the results obtained with the 2 modelling approaches. Results showed that all parameters obtained using the pooled data approach were within the $90 \%$ CI from the bootstrapping analysis, indicating that both the pooled data approach and bootstrapping are reliable methods for the analysis of the presented type of data.

The metabolites M3G and M6G were detected in both species. To our knowledge, this study is the first to report the presence of the morphine metabolite M6G in the plasma of a teleost. Although the degree of metabolism could not be determined accurately, it appeared to be low. The disposition profile for M3G corresponded well with the results of Newby et al. (2008) who found a maximum level of $\sim 0.8 \mathrm{mg} \mathrm{l}^{-1}$ after $24 \mathrm{~h}$ in rainbow trout that were given $40 \mathrm{mg} \mathrm{kg}^{-1}$ morphine sulphate intraperitoneally (i.p.); here, we found $C_{\max }$ values of $0.7 \mathrm{mg} \mathrm{l}^{-1}$ in goldfish that were given $40 \mathrm{mg} \mathrm{kg}^{-1}$, and $1.2 \mathrm{mg} \mathrm{l}^{-1}$ in salmon that were given $100 \mathrm{mg} \mathrm{kg}^{-1}$.

The half-lives of morphine in plasma were similar for the 2 species, as the average value for each species was within the $90 \% \mathrm{CI}$ for the other species. The same was the case for the volume of distribution and clearance. Goldfish and salmon belong to different orders of teleosts, thus differences might be expected. The parameters also corresponded well with similar values reported by Newby et al. (2008) for rainbow trout, but contrasts with the reported half-life of elimination for goldfish that was found to be $37 \mathrm{~h}$ after intraperitoneal (i.p.) injection (Newby et al. 2009). Temperature influences metabolism in fish (Clarke \& Johnston 1999), but as the temperature in the current experiment was $4^{\circ} \mathrm{C}$ lower than that used by Newby et al. (2009), this cannot explain the lower half-life and thus faster metabolism found in goldfish in the current experiment. In the present study, morphine was i.m. administered, while it was i.p. administered in the study of Newby et al. (2009); however, this cannot fully explain the discrepancy since the concentration versus time curves for morphine are quite similar between the 2 studies (see 

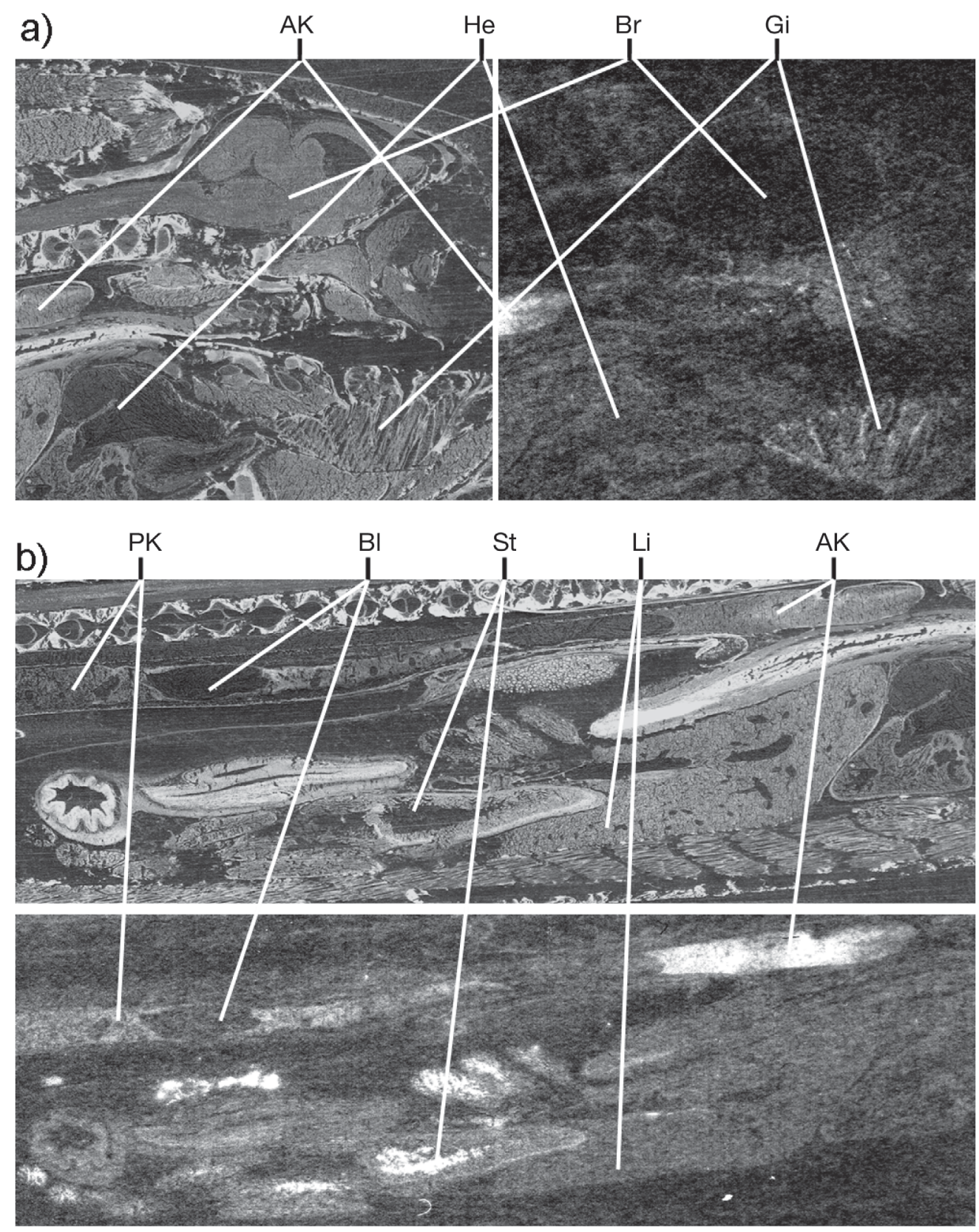

Fig. 4. Salmo salar. Autoradiography images. (a) Sagittal section, head, 1 h. Left image: tissue section, right image: corresponding autoradiographic image. Polarity is reversed, and lighter areas correspond to higher levels of radioactivity. AK: anterior kidney, He: heart, Br: brain, Gi: gills. The highest level of activity is found in the anterior kidney. Activity in the heart muscle is low, and the brain makes a negative image on the film. (b) Sagittal section, peritoneal cavity, $1 \mathrm{~h}$. Top image: tissue section; bottom image: corresponding autoradiographic image. PK: posterior kidney, Bl: blood, St: stomach, Li: liver. Anterior and posterior parts of the kidney have a high level of activity, as has the mucosa and lumen of the gastrointestinal tract. Activity can also be detected in the liver, whereas blood makes a negative image

our Fig. 2 and Fig. 4 in Newby et al. 2009), and the time at which the maximum concentration was reached was $30 \mathrm{~min}$ for both studies. Metacaine was used in the present study, but not in the study of Newby et al. (2009), and could have influenced metabolism. However, metacaine does not influence glucuronidation in rainbow trout liver in vitro (Kolanczyk et al. 2003), and is therefore not a likely explanation of the difference in results between the 2 studies. However, one factor that might have contributed to the observed differences is that the goldfish used in the 2 studies are from different stocks and may differ genetically. Genotype may influence the metabolism of opioids (Stamer \& Stuber 2007). 


\section{Autoradiography}

The relatively high levels of morphine in the liver may be caused by glucuronidation of morphine in this organ, and the high levels in the posterior kidney most likely reflects accumulation of morphine for excretion, as supported by the detection of urine bladder activity after $8 \mathrm{~h}$. The levels detected in the anterior kidney is more difficult to explain, but could possibly be due to binding to leucocytes. The anterior kidney is an important immunological organ in fish, and produces leucocytes in addition to erythrocytes (Kryvi \& Totland 1997). Morphine receptors have been found on the leucocytes of vertebrates (Sharp 2006), including teleosts (Chadzinska et al. 1997). The whole-body autoradiography results mainly coincided with the results from the scintillation count. In addition, high activity was detected in the mucosa and lumen of the gastrointestinal tract. This could be interpreted as morphine being excreted through the gastrointestinal tract. In sheep, the gut:blood partition coefficient was 11.0 (Sloan et al. 1991), indicating that this route of excretion is also important in mammals. After 0.5 and $1 \mathrm{~h}$, strong radioactivity was detected over the injection site, but this was no longer present at $8 \mathrm{~h}$, indicating that any precipitation at the injection site due to common ion effect, pH and temperature (Stevens \& Balahura 2007) lasted no longer than 8 h. As brain tissue was available in only a few fish after sectioning, radioactivity levels in different brain areas could not be determined by scintillation counting. The few samples that were taken indicated even lower levels as in the spinal cord, and this is supported by the autoradiography images. The autoradiograms showed no detectable activity in the brain at any time point (Fig. 4). This contrasts with findings in rats, where the concentration ratio in blood and brain subcortex was close to 1 for several hours after an intravenous injection (Plomp et al. 1981). The low accessibility of morphine to the fish brain may partly explain why relatively high doses of morphine have been used to obtain an analgesic effect in fish compared to mammals (Yeomans et al. 1996, Sneddon 2003). However, even low concentrations can have an effect provided the efficacy at the receptor is high. The efficacy of morphine on the fish $\mu$-opioid receptor is currently unknown, and needs to be addressed in future studies. In addition, the route of administration greatly influences the plasma concentration needed for analgesia in fish (Newby et al. 2009). The reason for this effect of administration route as well as the reasons for the low accessibility of morphine to the fish brain when i.m. injected need to be investigated in future experiments.
Acknowledgements. This study was financed by the Norwegian Research Council grant no. 159667/S40, and was approved by the Norwegian Animal Research Authority in accordance with the Animal Welfare Act (1974) and the Regulation of Animal Experimentation (1996) in Norway.

\section{LITERATURE CITED}

Andersen G, Christrup L, Sjøgren P (2003) Relationships among morphine metabolism, pain and side effects during long-term treatment: an update. J Pain Symptom Manag 25:74-91

Ashley PJ, Sneddon LU, McCrohan CR (2007) Nociception in fish: stimulus-response properties of receptors on the head of trout (Oncorhynchus mykiss). Brain Res 1166:47-54

Baggot JD (2001) The physiological basis of veterinary clinical pharmacology. Blackwell Science, Oxford

Braithwaite VA, Boulcott P (2007) Pain perception, aversion and fear in fish. Dis Aquat Org 75:131-138

Carpenter J, Bithell J (2000) Bootstrap confidence intervals: when, which, what? A practical guide for medical statisticians. Stat Med 19:1141-1164

Chadzinska M, Józefowski S, Bigaj J, Plytycz B (1997) Morphine modulation of thioglycollate-elicited peritoneal inflammation in the goldfish, Carassius auratus. Arch Immunol Ther Exp (Warsz) 45:321-327

Clarke A, Johnston NM (1999) Scaling of metabolic rate with body mass and temperature in teleost fish. J Anim Ecol 68:893-905

- Dahan A, van Dorp E, Smith T, Yassen A (2008) Morphine-6glucuronide (M6G) for postoperative pain relief. Eur J Pain 12:403-411

Davison AC, Hinkley DV (1997) Bootstrap methods and their application. Cambridge University Press, Cambridge

- Efron B (1987) Better bootstrap confidence intervals. J Am Stat Assoc 82:171-200

Efron B, Tibshirani RJ (1993) Better bootstrap confidence intervals: an introduction to the bootstrap. Chapman \& Hall, New York

Ehrensing RH, Michell GF, Kastin AJ (1982) Similar antagonism of morphine analgesia by MIF-1 and Naloxone in Carassius auratus. Pharmacol Biochem Behav 17:757-761

Hasselström J, Säwe J (1993) Morphine pharmacokinetics and metabolism in humans. Clin Pharmacokinet 24: 344-354

Hewett K, Dickenson AH, McQuay HJ (1993) Lack of effect of morphine-3-glucuronide on the spinal antinociceptive actions of morphine in the rat: an electrophysiological study. Pain 53:59-63

> Horsberg TE (1994) Experimental methods for pharmacokinetic studies in salmonids. Annu Rev Fish Dis 4:345-358

> King CD, Devine DP, Vierck CJ, Mauderli A, Yezierski RP (2007) Opioid modulation of reflex versus operant responses following stress in the rat. Neuroscience 147: 174-182

Kolanczyk RC, Fitzsimmons PN, Mckim JM, Erickson RJ, Schmieder PK (2003) Effects of anesthesia (tricaine methanesulfonate, MS222) on liver biotransformation in rainbow trout (Oncorhynchus mykiss). Aquat Toxicol 64: $177-184$

Kryvi H, Totland GK (1997) Fiskeanatomi. Høyskoleforlaget AS, Kristiansand

Martinsen B, Sohlberg S, Horsberg TE, Bruke M (1993) Single-dose kinetic study of sarafloxacin after intravascular and oral administration to cannulated Atlantic salmon (Salmo salar) held in sea water at $12^{\circ} \mathrm{C}$. Aquaculture 118: $49-52$ 
Newby NC, Mendonca PC, Gamperl K, Stevens ED (2006) Pharmacokinetics of morphine in fish: winter flounder (Pseudopleuronectes americanus) and seawater-acclimated rainbow trout (Oncorhynchys mykiss). Comp Biochem Physiol C 143:275-283

Newby NC, Gamperl AK, Stevens ED (2007) Cardiorespiratory effects and efficacy of morphine sulfate in winter flounder (Pseudopleuronectes americanus). Am J Vet Res 68:592-597

Newby NC, Robinson JW, Vachon P, Beaudry F, Stevens ED (2008) Pharmacokinetics of morphine and its metabolites in freshwater rainbow trout (Oncorhyncus mykiss). J Vet Pharmacol Ther 31:117-127

Newby NC, Wilkie MP, Stevens ED (2009) Morphine uptake, disposition, and analgesic efficacy in the common goldfish (Carassius auratus). Can J Zool 87:388-399

Nordgreen J, Garner JP, Janczak AM, Ranheim B, Muir WM, Horsberg TE (2009) Thermonociception in fish: effects of two different doses of morphine on thermal threshold and post-test behaviour in goldfish (Carassius auratus). Appl Anim Behav Sci 119:101-107

Pezalla PD (1983) Morphine-induced analgesia and explosive motor behavior in an amphibian. Brain Res 273:297-305

Plomp GJJ, Maes RAA, Vanree JM (1981) Disposition of morphine in rat brain: relationship to biological activity. J Pharmacol Exp Ther 217:181-188

Rang HP, Dale MM, Ritter JM (1999) Pharmacology. Churchill Livingstone, Edinburgh

Rose JD (2007) Anthropomorphism and 'mental welfare' of fishes. Dis Aquat Org 75:139-154

Sharp BM (2006) Multiple opioid receptors on immune cells modulate intracellular signaling. Brain Behav Immun 20: 9-14

Editorial responsibility: Roland Anderson, Seattle, Washington, USA
Sloan PA, Mather LE, McLean CF, Rutten AJ and others (1991) Physiological disposition of i.v. morphine in sheep. Br J Anaesth 67:378-386

Smith MT, Watt JA, Cramond T (1990) Morphine-3glucuronide - a potent antagonist of morphine analgesia. Life Sci 47:579-585

Sneddon LU (2003) The evidence for pain in fish: the use of morphine as an analgesic. Appl Anim Behav Sci 83: 153-162

Sohlberg S, Aulie A, Soli NE (1994) Temperature-dependent absorption and elimination of flumequine in rainbow trout (Oncorhynchus mykiss Walbaum) in fresh water. Aquaculture 119:1-10

Sohlberg S, Martinsen B, Horsberg TE, Soli NE (1996) Evaluation of the dorsal aorta cannulation technique for pharmacokinetic studies in Atlantic salmon (Salmo salar) in sea water. J Vet Pharmacol Ther 19:460-465

Soivio A, Nyholm K, Westman K (1975) A technique for repeated sampling of the blood of individual resting fish. J Exp Biol 63:207-217

Stamer UM, Stuber F (2007) The pharmacogenetics of analgesia. Expert Opin Pharmacother 8:2235-2245

- Stevens ED, Balahura RJ (2007) Aspects of morphine chemistry important to persons working with cold-blooded animals, especially fish. Comp Med 57:161-166

Urien S, Brain E, Bugat R, Pivot X and others (2005) Pharmacokinetics of platinum after oral or intravenous cisplatin: a phase 1 study in 32 adult patients. Cancer Chemother Pharmacol 55:55-60

Yeomans DC, Pirec V, Proudfit HK (1996) Nociceptive responses to high and low rates of noxious cutaneous heating are mediated by different nociceptors in the rat: behavioral evidence. Pain 68:133-140

Submitted: May 14, 2009; Accepted: September 16, 2009 Proofs received from author(s): December 3, 2009 